\title{
ANAIS DOS ENEQ: O QUE NOS DIZEM SOBRE A ÁREA DE EDUCAÇÃO EM QUÍMICA NO BRASIL?
}

Daniela Marques Alexandrino ${ }^{\mathrm{a}}$, Paulo Sergio Bretones ${ }^{\mathrm{b}}$ e Salete Linhares Queiroz $^{\mathrm{a}, *,(1)}$

anstituto de Química de São Carlos, Universidade de São Paulo, 13560-970 São Carlos - SP, Brasil

${ }^{b}$ Departamento de Metodologia de Ensino, Universidade Federal de São Carlos, 13565-905 São Carlos - SP, Brasil

Recebido em 03/04/2021; aceito em 04/10/2021; publicado na web em 22/10/2021

\begin{abstract}
ENEQ ANNALS: WHAT DO THEY TELL US ABOUT CHEMISTRY EDUCATION AREA IN BRAZIL? Academic production on Chemistry Education in Brazil is abundant. The network of participants that contribute to it is vast, spread across all geographic regions. This network is responsible for carrying out actions that have led to consolidating the area of Chemistry Education. This article analyzes all the annals now available from the Encontro Nacional de Ensino de Química (ENEQ) and establishes relationships between events that took place at the conferences and the previously mentioned consolidation (analysis period: 1982 to 2018). In addition, the authorship of the works presented at ENEQ (analysis period: 1982 to 2010) was investigated, enabling us to identify professionals who offered relevant contributions to help construct the current scenario in the area.
\end{abstract}

Keywords: ENEQ; chemistry education; authorship.

\section{INTRODUÇÃO}

A produção acadêmica sobre o ensino de química no Brasil é abundante, sendo inclusive alvo de trabalhos do tipo Estado da Arte. ${ }^{1}$ A rede de investigadores que a alimenta é ampla, espalha-se por todos as regiões geográficas do país, e assume a responsabilidade pela realização de eventos, redação de documentos científicos, publicação de revistas, orientação de mestrandos e doutorandos em cursos de pós-graduação stricto sensu, atuação em cursos de pós-graduação lato sensu, dentre outras ações que levaram à consolidação da área de Educação em Química. ${ }^{2-5} \mathrm{O}$ conhecimento de fatores e a identificação de lideranças que contribuíram para tanto são relevantes, tendo em vista a preservação da memória da área. Considerando que são escassos os conhecimentos no que tange a tais aspectos, ${ }^{2-5}$ o presente trabalho tem como objetivo analisar todos os anais ora disponíveis do Encontro Nacional de Ensino de Química (ENEQ), de modo a estabelecer relações entre acontecimentos que tiveram espaço no evento e a referida consolidação (período de análise: 1982 a 2018), assim como identificar a autoria dos trabalhos apresentados, com posterior investigação do quantitativo de publicações dos autores, almejando o conhecimento de importantes atores nesse cenário (período de análise: 1982 a 2010).

Na atualidade, o ENEQ é um importante espaço de disseminação de conhecimento, propiciando ambiente de encontro de pesquisadores da área de Educação em Química, professores de diferentes níveis de escolaridade, assim como estudantes de graduação e pósgraduação. A sua relevância repousa no fato de divulgar, além dos resultados de investigações, relatos de experiências em ambientes de ensino, a fim de, principalmente, melhorar situações vinculadas à docência. A origem do evento está associada à criação da Secretaria Regional da Sociedade Brasileira de Química (SBQ), no estado do Rio Grande do Sul, a partir da qual ocorreu a mobilização para promoção de encontros sobre o ensino de química. Nesse contexto, no ano de 1980, Attico Inacio Chassot, à frente da recém-constituída regional gaúcha, organizou o I Encontro de Debates sobre o Ensino de Química (EDEQ). ${ }^{3}$ No ano seguinte ocorreu o II EDEQ. Na oportunidade, Roseli Pacheco Schnetzler foi convidada por Attico Inacio Chassot a participar da reunião e, com base nas articulações

*e-mail: salete@iqsc.usp.br da comunidade gaúcha de educadores químicos, encontrou "o exemplo e o estímulo para propor e organizar um outro tipo de encontro, o ENEQ" (p.18). ${ }^{3}$

O ENEQ teve a sua vigésima edição concluída no mês de março do corrente ano, na modalidade remota, devido à pandemia causada pelo coronavírus, Covid-19. ${ }^{6}$ Neste manuscrito todos os eventos que o antecederam tiveram seus anais investigados no que diz respeito a local, número de trabalhos apresentados, comissão organizadora, atividades realizadas e apoio de agências de fomento; adicionalmente, a autoria dos trabalhos, no período de 1982 a 2010, foi alvo de escrutínio. Dessa forma, no tópico Evolução dos ENEQ (1982 a 2018) foram estabelecidas as relações mencionadas no primeiro parágrafo e no tópico Autoria nos ENEQ (1982 a 2010) foi traçado um perfil dos recursos humanos pioneiros e dos que foram surgindo na área. Para tanto, os nomes dos autores foram organizados numa planilha de Excel $^{\circledR}$, depois foram abreviados, com exceção do último sobrenome. Posteriormente, foi invertida a posição, deixando o sobrenome seguido das iniciais dos primeiros nomes, sem espaçamento entre eles, e uma nuvem de palavras foi gerada no programa online Tag Crowd®. Os nomes mais recorrentes foram então organizados na nuvem, em vários tamanhos, com base no número de menções feitas a eles. Os autores com maior quantidade de trabalhos apresentados, ao longo do período em foco, tiveram sua produção acadêmica discutida, na perspectiva das contribuições ao ensino de química.

\section{EVOLUÇÃO DOS ENEQ (1982 A 2018)}

\section{Primeira década}

No ano de 1982, foi realizada em Campinas, na Universidade Estadual de Campinas (UNICAMP), a 34. ${ }^{a}$ Reunião Anual da Sociedade Brasileira para o Progresso da Ciência (SBPC), concomitantemente à 5 . $^{\text {a }}$ Reunião Anual da SBQ. Na ocasião também ocorreu o I ENEQ, com periodicidade bienal, quando foram apresentados 40 trabalhos. $^{4}$

O II ENEQ foi realizado em 1984, na Universidade de São Paulo (USP), em São Paulo, concomitante à $36 .^{a}$ Reunião Anual da SBPC e à $7 .{ }^{a}$ Reunião Anual da SBQ. Com relação a essa edição, que teve 16 trabalhos apresentados, os resumos só foram publicados nos anais do III ENEQ. ${ }^{4}$ 
O III ENEQ foi realizado em 1986, na Universidade Federal do Paraná (UFPR), em Curitiba, concomitante à 38. ${ }^{a}$ Reunião Anual da SBPC e à 9. ${ }^{a}$ Reunião Anual da SBQ. Consolidava-se a tradição de realizar os encontros bienalmente e no mês de julho. Foram apresentados 52 trabalhos. $^{4}$

O IV ENEQ foi realizado em 1988, na USP, em São Paulo, concomitante à 40. ${ }^{\mathrm{a}}$ Reunião Anual da SBPC e à 11 . $^{\mathrm{a}}$ Reunião Anual da SBQ. Essa foi a última edição conjunta com a Reunião Anual da SBQ, quando foram apresentados 50 trabalhos. ${ }^{4} \mathrm{Na}$ ocasião foi constituída a Divisão de Ensino da Sociedade Brasileira de Química (DED), configurando-se como um espaço na comunidade de químicos para estudos e pesquisas sobre o ensino de química. ${ }^{2} \mathrm{~A}$ abreviatura DED é recorrentemente usada em artigos que tratam da evolução da área de Educação em Química, ${ }^{5}$ no entanto, atualmente é adotada a abreviatura ED.

O V ENEQ foi realizado em 1990, na Universidade Federal do Rio Grande do Sul (UFRGS), em Porto Alegre, concomitante à 42. ${ }^{\text {a }}$ Reunião Anual da SBPC. Foram apresentados 19 trabalhos. $^{4}$

O Quadro 1 ilustra a distribuição dos ENEQ por edição (ano), local, comissão organizadora e agências de fomento, durante a primeira década.

Além do apoio institucional das universidades que sediaram o encontro e da Divisão de Ensino da Sociedade Brasileira de Química, bancos, editoras e livrarias, dentre outros segmentos comercias, ofereceram suporte à realização dos eventos. Ademais, as várias edições foram apoiadas pelas agências federais de fomento, Coordenação de Aperfeiçoamento de Pessoal de Nível Superior (CAPES) e Conselho Nacional de Desenvolvimento Científico e Tecnológico (CNPq). A Fundação de Amparo à Pesquisa do Estado de São Paulo (FAPESP) apoiou duas edições. A participação da CAPES ocorreu por meio do Subprograma Educação para a Ciência (SPEC), do Programa de Apoio ao Desenvolvimento Científico e Tecnológico (PADCT). ${ }^{7}$

As ações do SPEC instigaram a comunidade acadêmica a organizar-se em torno das questões próprias e particulares do processo de ensino e aprendizagem e a enfrentar desafios como: ressignificar cursos de formação inicial e continuada de professores, rever a relação entre universidades e Educação Básica e fomentar a articulação dos pesquisadores e docentes com seus pares. ${ }^{7}$ O SPEC também contribuiu para a realização dos ENEQ e de outros eventos de abrangência regional voltados ao ensino de química, além da criação e manutenção inicial da QNEsc., ${ }^{3,7}$

Cabe destacar que durante a primeira década os anais dos eventos eram impressos, contendo os resumos e a programação realizada em cada um. Com exceção da segunda edição, que foi impressa em conjunto com a terceira, os demais tiveram seus volumes organizados separadamente.

\section{Segunda década}

O VI ENEQ foi realizado em 1992, na USP, em São Paulo, concomitantemente ao I Encontro Sudeste de Ensino de Química (ESEQ) e à 44. ${ }^{a}$ Reunião Anual da SBPC. Essa foi a última edição conjunta com a Reunião Anual da SBPC. Foram apresentados 22 trabalhos. $^{4}$

O VII ENEQ foi realizado em 1994, na Universidade Federal de Minas Gerais (UFMG), em Belo Horizonte, conjuntamente com o II ESEQ. A partir dessa edição, o evento passou a ter um tema central, neste foi A formação do professor de química e ciências. Foram apresentados 42 trabalhos, incluindo a reapresentação de sete, que haviam inicialmente integrado a programação de eventos como o $7 .^{\circ}$ Encontro Regional da SBQ - MG e a 17. ${ }^{a}$ RASBQ. ${ }^{4}$

No evento, foi definida a criação da revista Química Nova na Escola (QNEsc), importante veículo de divulgação e socialização dos trabalhos desenvolvidos pelos diferentes grupos dispersos pelo país. ${ }^{8}$ Outrossim, foi a primeira vez que se produziu um volume completo sobre o evento, com apresentação de ficha catalográfica e a publicação de todo o material apresentado. ${ }^{4}$

O VIII ENEQ foi realizado em 1996, na Universidade Federal de Mato Grosso do Sul (UFMS), em Campo Grande, concomitante ao VIII Encontro Centro-Oeste de Debates sobre o Ensino de Química e Ciências (ECODEDC). O tema central dessa edição foi A química para a formação do cidadão. Foram apresentados 67 trabalhos, incluindo a reapresentação de catorze, que haviam inicialmente integrado a programação de eventos como a $19^{\mathrm{a}} \mathrm{RASBQ} .{ }^{4}$ De caráter inovador nesta edição foi a realização do I Workshop de Pesquisa em Ensino de Química, com a ocorrência de sessões de debates em torno de temas que abordavam aspectos teórico-metodológicos do campo de investigação na área. ${ }^{4}$

O IX ENEQ foi realizado em 1998, na Universidade Federal de Sergipe (UFS), em Aracaju, com o tema central $O$ desafio de ensinar no século XXI, cujo objetivo foi disseminar resultados de pesquisas, a fim de possibilitar renovações metodológicas e atualização de conhecimentos. Pela primeira vez, o evento não foi realizado no mês de julho, devido à greve dos professores, no ano anterior. ${ }^{4}$ Foram apresentados 66 trabalhos, incluindo a reapresentação de dezesseis, que haviam inicialmente integrado a programação de eventos como a $21^{\text {a }}$ RASBQ. ${ }^{4}$

O X ENEQ foi realizado em 2000, na Pontifícia Universidade Católica do Rio Grande do Sul (PUC-RS), em Porto Alegre, concomitante ao II Encontro Latino-Americano de Ensino de Química (ELEQ) e ao XX EDEQ, com o tema central Educação em química pela pesquisa: um desafio para a sala de aula. A novidade nessa edição foi a criação dos Grupos de Reflexão,

Quadro 1. Edições dos ENEQ, comissão organizadora e agências de fomento: primeira década

\begin{tabular}{|c|c|c|}
\hline $\begin{array}{c}\text { Edição } \\
\text { Ano) Local }\end{array}$ & Comissão Organizadora & Agências De Fomento \\
\hline $\begin{array}{c}\text { I (1982) } \\
\text { Campinas }\end{array}$ & $\begin{array}{c}\text { Ana Maria da Costa Ferreira, Gilmar da Cunha Trivelato, Maria Eunice Ribeiro } \\
\text { Marcondes, Mansur Lutfi e Roseli Pacheco Schnetzler }\end{array}$ & CAPES, FAPESP, CNPq \\
\hline $\begin{array}{c}\text { II (1984) } \\
\text { São Paulo }\end{array}$ & $*$ & $*$ \\
\hline $\begin{array}{c}\text { III (1986) } \\
\text { Curitiba }\end{array}$ & $\begin{array}{c}\text { Angélica Ambrogi, Júlio Cezar Foschini Lisbôa, Isaura Kuwabara, Maria Eunice } \\
\text { Ribeiro Marcondes, Maria Helena Roxo Beltran e Roseli Pacheco Schnetzler }\end{array}$ & CAPES, FAPESP, CNPq \\
\hline $\begin{array}{c}\text { IV (1988) } \\
\text { São Paulo }\end{array}$ & $\begin{array}{c}\text { Angélica Ambrogi, Isaura Maria Vidotti, Júlio Cezar Foschini Lisbôa, Maria Eunice } \\
\text { Ribeiro Marcondes e Roseli Pacheco Schnetzler }\end{array}$ & CAPES, CNPq \\
\hline $\begin{array}{c}\text { V (1990) } \\
\text { Porto Alegre }\end{array}$ & $\begin{array}{c}\text { Edni Oscar Schroeder, Maria Eunice Ribeiro Marcondes, Maurivan Güntzel Ramos, } \\
\text { Attico Inacio Chassot, José Claudio Del Pino, Tania Denise Miskinis Salgado e Tania } \\
\text { Maria Haas Costa }\end{array}$ & CAPES \\
\hline
\end{tabular}

Nota: *Informações não disponíveis nos anais da edição. 
Quadro 2. Edições dos ENEQ, comissão organizadora e agências de fomento: segunda década

\begin{tabular}{|c|c|c|}
\hline $\begin{array}{c}\text { Edição (Ano) } \\
\text { Local }\end{array}$ & Comissão Organizadora & Agências de Fomento \\
\hline $\begin{array}{c}\text { VI (1992) } \\
\text { São Paulo }\end{array}$ & $\begin{array}{c}\text { Luiz Otávio Fagundes Amaral, Maria Eunice Ribeiro Marcondes, Roseli Pacheco } \\
\text { Schnetzler e Tania Guimarães Santa-Rita }\end{array}$ & CAPES \\
\hline $\begin{array}{c}\text { VII (1994) } \\
\text { Belo Horizonte }\end{array}$ & $\begin{array}{c}\text { Andréa Horta Machado, Eduardo Fleury Mortimer, Gerson de Souza Mól, Lilavate } \\
\text { Izapovitz Romanelli, Luiz Adolfo Kangussu Gomes, Luiz Otávio Fagundes Amaral, } \\
\text { Maria Emília Caixeta de Castro Lima e Rosária Justi Celano Torres }\end{array}$ & FAPEMIG, FUNDEP, CNPq, CAPES \\
\hline $\begin{array}{c}\text { VIII (1996) } \\
\text { Campo Grande }\end{array}$ & $\begin{array}{c}\text { Dênis Pires de Lima, José Francisco Vianna, Maria Celina Recena Aydos, Maria Helena } \\
\text { Costa e Onofre Salgado Siqueira }\end{array}$ & CNPq \\
\hline $\begin{array}{c}\text { IX (1998) } \\
\text { Aracaju }\end{array}$ & $\begin{array}{c}\text { Djalma Andrade, Luciene Pimenta Romão, Nivam Bezerra da Costa Júnior, Perícles } \\
\text { Barreto Alves, José do Patrocínio Hora Alves, Ruth Sales Gama de Andrade, Maria da } \\
\text { Glória Menezes Santos e Patrícia Soares de Lima }\end{array}$ & CNPq, FAPESE \\
\hline $\begin{array}{c}\text { X (2000) } \\
\text { Porto Alegre }\end{array}$ & $\begin{array}{c}\text { Maurivan Güntzel Ramos, Berenice Alvares Rosito, Concetta Schifino Ferraro, Luiz } \\
\text { Ernani Aguiar Silva, Rejane Rolim de Azambuja e Roque Moraes }\end{array}$ & FAPERGS, CNPq \\
\hline
\end{tabular}

Grupos de Pesquisa e Relatos de Pesquisa. Os Grupos de Reflexão substituíram os habituais minicursos, com a intenção de oferecer momentos de debate e reflexão suscitados pela apresentação de conhecimentos e vivências de seus coordenadores. Já os Grupos de Pesquisa foram idealizados de modo a que os pesquisadores pudessem aprofundar a discussão sobre seus trabalhos. Os Relatos de Pesquisa destinaram-se à apresentação oral e de pôsteres. ${ }^{4}$ Foram apresentados 140 trabalhos, incluídos nesse número os resumos vinculados aos Grupos de Pesquisa e Relatos de Pesquisa, e desconsiderados aqueles dos Grupos de Reflexão, devido ao caráter que possuem de aplicação de uma atividade didática junto aos participantes do evento. ${ }^{4}$

O Quadro 2 ilustra a distribuição dos ENEQ por edição (ano), local, comissão organizadora e agências de fomento, durante a segunda década.

Além do apoio institucional das universidades que sediaram o encontro e da Divisão de Ensino da Sociedade Brasileira de Química, os eventos também contaram com o apoio do Conselho Regional de Química (CRQ), da Fundação Augusto Franco e Fundação Vitae, de editoras, livrarias e agências de viagem, dentre outros segmentos comerciais. Em relação às agências de fomento, duas federais $(\mathrm{CNPq}$ e CAPES) e três estaduais contribuíram para a realização: Fundação de Amparo à Pesquisa do Estado de Minas Gerais (FAPEMIG); Fundação de Amparo à Pesquisa e Extensão de Sergipe (FAPESE); Fundação de Amparo à Pesquisa do Estado do Rio Grande do Sul (FAPERGS). Cabe ressaltar que durante a década de 1990 estava em vigência a segunda fase do SPEC.?

$\mathrm{Na}$ segunda década, assim como na primeira, os anais dos eventos contendo toda a programação e resumos dos trabalhos foram organizados e impressos.

\section{Terceira década}

O XI ENEQ foi realizado em 2002, na Universidade Federal Rural de Pernambuco (UFRPE), em Recife, com o tema central Ciência, Tecnologia, Ambiente e Sociedade na Educação Química: $o$ desafio da interação. A partir dessa edição, o texto do resumo deveria adequar-se em uma página de acordo com o template do trabalho, similar ao que temos atualmente. Deveriam estar inseridos: o título do trabalho; os nomes dos autores; a categoria de cada autor, dentre elas, pesquisador (PQ), professor do Ensino Fundamental/ Médio (FM), pós-graduando (PG) ou graduando (IC); instituição de vínculo de cada autor e três palavras-chave. Além disso, a construção do texto deveria contemplar as seções: Introdução; Resultados e Discussão; Conclusões; Agradecimentos (se plausivel); Referências Bibliográficas. Foram apresentados 181 trabalhos. $^{4}$
O XII ENEQ foi realizado em 2004, na Universidade Federal de Goiás (UFG), em Goiânia, concomitante ao III Encontro Centro-Oeste de Química (ECOQ), ao XIII ECODEQ e à V Semana do Químico. O tema central foi As novas politicas educacionais e seus impactos no ensino de química. ${ }^{9} \mathrm{O}$ evento foi realizado com o objetivo de fomentar a participação cada vez mais consciente e transformadora da comunidade de educadores químicos na construção efetiva da cidadania e contou com a colaboração e apoio de outras instituições: Universidade Estadual de Goiás (UEG); Universidade de Brasília (UnB); Centro Federal de Educação Tecnológica de Goiás (CEFETGO). Foram apresentados 267 trabalhos. $^{4}$

O XIII ENEQ foi realizado em 2006, na UNICAMP, em Campinas, concomitante ao VI Simpósio de Profisssionais do Ensino de Química (SIMPEQ) e o III Encontro Paulista de Pesquisa em Ensino de Química (EPPEQ). O encontro atingiu a sua $13^{\text {a }}$ edição e comemorou os 25 anos de congregação da comunidade dos educadores químicos. Por isso, nesse ano o evento foi organizado em torno do tema central Educação em Química no Brasil - 25 anos de ENEQ. Foram apresentados 334 trabalhos. $^{4}$

O evento foi realizado com a colaboração e apoio de outras universidades paulistas que também abrigam cursos de química, especialmente de Licenciatura: USP; Universidade Federal de São Carlos (UFSCar); Universidade Estadual Paulista (UNESP); PUC-Campinas; Universidade Metodista de Piracicaba (UNIMEP); Universidade São Francisco (USF); Fundação Santo André (FSA). Ao atingir a marca dos 25 anos, o ENEQ avaliou esse campo como produtor de conhecimento específico, a partir de sua constituição híbrida entre a química e a educação. Sendo assim, foram debatidas questões que viabilizassem a emergência de discussões acerca da contribuição da química na formação humana e social, buscando-se avanços na compreensão da especificidade do conhecimento químico. ${ }^{4}$

$\mathrm{Na}$ ocasião, além dos habituais resumos de uma página, foram aceitos trabalhos completos. Essa modalidade foi apresentada em texto de aproximadamente doze páginas, com 5000 palavras, conforme template. Nas edições anteriores, as sessões coordenadas foram propostas a partir da seleção dos resumos submetidos, enquanto que na $13^{\text {a }}$ edição ocorreu a realização das sessões coordenadas a partir dos trabalhos completos, por temas, que foram adotados até o último ENEQ com pequenas variações, a saber: Currículo e Avaliação; Ensino e Aprendizagem; Ensino e História da Ciência; Espaços Não-Formais de Ensino; Experimentação no Ensino; Formação de Professores; Linguagem e Cognição; Materiais Didáticos; Tecnologias da Informação e Comunicação. ${ }^{4}$ Os eixos temáticos propostos serviram para promover o debate, além de facilitar o envio e avaliação dos trabalhos. No decorrer das edições, muitos temas foram mantidos e outros complementados para o formato que temos atualmente. ${ }^{4}$ 
O XIV ENEQ foi realizado em 2008, na UFPR, em Curitiba, em parceria com: Universidade Estadual de Ponta Grossa (UEPG); Universidade Estadual de Londrina (UEL); Universidade Estadual de Maringá (UEM); Universidade Estadual do Oeste do Paraná (Unioste); Universidade Estadual do Centro-Oeste (Unicentro). O tema central foi Conhecimento químico: desafios e possibilidades da pesquisa e da ação docente. Os trabalhos foram distribuídos de acordo com as temáticas propostas no XIII ENEQ, acrescida de uma nova: Ensino e Cultura e de uma modificação: a temática Ensino e História da Ciência passou a ser denominada por História e Filosofia da Ciência no Ensino. Foram apresentados 462 trabalhos. ${ }^{4}$

Nessa edição, foi lançada a I Mostra de Materiais Didáticos (MOMADIQ), cujo objetivo foi reunir a produção recente que poderia ser comercializada, ou não, de materiais didáticos relacionados à química (livros e materiais didáticos e/ou paradidáticos, kits de experimentos, simulações, CD-ROM, jogos, softwares etc.), permitindo o compartilhamento de iniciativas, muitas vezes isoladas, existentes em vários pontos do país. O MOMADIQ configurou-se, portanto, como uma importante iniciativa, de caráter inovador, que acrescentou outras produções ao ENEQ, além das usuais. ${ }^{4}$

O XV ENEQ foi realizado em 2010, no Centro de Ensino Fundamental GAN (CEF-GAN), em Brasília, foi a primeira edição que ocorreu em uma escola pública de ensino fundamental e a UnB teve a incumbência de organizá-lo, em parceria com duas outras instituições de ensino superior (IES) da região, a UFG e a Universidade Federal do Mato Grosso (UFMT). O tema central foi A formação do professor de química e os desafios da sala de aula, com destaque para propostas que contribuem para a superação das necessidades formativas dos professores, frente aos diferentes contextos de sala de aula. ${ }^{4,10}$

No evento ocorreu sessão comemorativa dos quinze anos da QNEsc. A sessão contou com a participação de editores da QNEsc e de revistas internacionais, que fomentaram o debate sobre a relevância da revista na formação inicial e continuada de professores de química, além da sua contribuição como espaço privilegiado para a divulgação da pesquisa na área. Foram apresentados 794 trabalhos. ${ }^{4}$ Com relação ao número de trabalhos indicado, para esta edição cabe uma importante observação: o Editorial do evento, publicado no site http://www.sbq.org.br/eneq/xv/editorial.htm, afirma que "Foram submetidos cerca de 300 trabalhos completos e mais de 500 resumos, refletindo o perfil e os avanços da comunidade de pesquisadores em Ensino de Química do país". No entanto, o acesso, no mesmo site, ao ícone "Listar todos os trabalhos", permite a visualização de apenas 568, o que não está de acordo com o Editorial. Para visualizar o número aproximado de trabalhos mencionado no Editorial é necessário que se tenha em mãos o CD-ROM completo do evento, porém, o ícone com essa denominação no site (Download do CD-ROM completo) não permite, atualmente (03 de abril de 2021), o download dos trabalhos nele contidos.

As novidades observadas nessa edição foram as Palestras Conjuntas, nas quais dois pesquisadores partilhavam o tempo e, após a exposição, ambos respondiam às perguntas formuladas pelos ouvintes. Os Temas de Debate, em substituição às mesas-redondas, também foram compostos por dois debatedores, que discutiram questões acerca da formação de professores e dos desafios enfrentados em sala de aula. ${ }^{4}$

Dando continuidade ao ocorrido na $14 .^{\text {a }}$ edição, foi realizada a II MOMADIQ. Os trabalhos foram distribuídos de acordo com as temáticas propostas no XIV ENEQ, acrescidas de duas novas: Ensino e Inclusão e Educação Ambiental. Houve a iniciativa de garantir que todos os trabalhos completos fossem apresentados em forma de comunicações orais e pôsteres impressos permaneceram expostos durante todo o evento, o que permitiu maior divulgação e intercâmbio dos pesquisadores e interessados nos temas apresentados nos respectivos resumos. ${ }^{4}$

O Quadro 3 ilustra a distribuição dos ENEQ por edição (ano), local, comissão organizadora e agências de fomento, durante a terceira década.

Os eventos receberam apoio de vários segmentos comerciais, como editoras e construtoras, além do apoio institucional das universidades sede dos encontros e da Divisão de Ensino da Sociedade Brasileira de Química, com destaque para as regionais do CRQ, presentes em três edições, e para a Fundação Vitae e Fundação Araucária. Em relação às agências, o CNPq e a CAPES fomentaram todas as edições. As agências Fundação de Amparo à Ciência e Tecnologia do Estado de Pernambuco (FACEPE) e FAPESP estiveram presentes, respectivamente, na $11^{\mathrm{a}}$ e na $13^{\mathrm{a}}$ edição.

Os anais dos eventos foram disponibilizados em formato de CD-ROM, a datar de 2004, e na internet, por meio dos sites das IES organizadoras das edições do evento, a partir de 2008.

\section{Quarta década}

O XVI ENEQ foi realizado em 2012, na Universidade Federal da Bahia (UFBA), em Salvador, concomitante ao X Encontro de Educação Química da Bahia (EDUQUI), cujo tema central foi $O$ ensino de química: consolidação dos avanços e perspectivas futuras. $\mathrm{O}$ evento foi realizado com a colaboração e apoio de outras IES do estado da Bahia: Universidade do Estado da Bahia (UNEB); Universidade Estadual de Santa Cruz (UESC); Universidade Estadual do Sudoeste da Bahia (UESB); Universidade Estadual de Feira de Santana (UEFS); Universidade Federal do Recôncavo da Bahia (UFRB), que também abrigam cursos de química, especialmente de Licenciatura. Essa edição comemorou os trinta anos de ENEQ. Segundo Soares, Mesquita e Rezende, foram apresentados 889 trabalhos. ${ }^{5}$

$\mathrm{Na} 16$. $^{\mathrm{a}}$ edição ocorreram a Reunião dos Coordenadores de Cursos de Licenciatura em Química e a mesa-redonda do Programa Institucional de Bolsa de Iniciação à Docência (PIBID) - consolidação dos avanços e perspectivas futuras. A programação do evento contou com a realização da III MOMADIQ e os trabalhos foram distribuídos de acordo com as temáticas propostas anteriormente, com a inserção de: Abordagens Ciência-Tecnologia-Sociedade (CTS); História e Filosofia da Química; Políticas Educacionais. A temática Espaços Não Formais de Ensino foi alterada para Educação em Espaços Não Formais e Divulgação Científica, enquanto História e Filosofia da Ciência no Ensino para História, Filosofia e Sociologia da Ciência no Ensino de Química. A temática Ensino e Cultura foi excluída. ${ }^{4}$

O XVII ENEQ foi realizado em 2014, na Universidade Federal de Ouro Preto (UFOP), em Ouro Preto, e teve como tema A integração entre pesquisa e escola abrindo possibilidades para um ensino de química melhor. Foram articulados debates acerca de mudanças significativas que ocorreram nas universidades brasileiras, como consequência de políticas públicas, a saber: a criação de novos cursos de Licenciatura em Química, por meio do plano de Reestruturação e Expansão das Universidades Federais (REUNI), a disseminação do PIBID e a implantação dos mestrados profissionais em rede nacional. Essas ações levaram à contratação de profissionais da área de Educação em Química para as universidades, com consequente criação e/ou consolidação de diversos grupos de pesquisa emergentes. . $^{411}$

Trabalhos apresentados no evento foram selecionados e publicados em número especial da QNEsc, evidenciando a estreita relação entre os ENEQ e a revista. Segundo Porto, Queiroz e Santos, foram apresentados 1066 trabalhos. ${ }^{11} \mathrm{Na} 17 .{ }^{\text {a }}$ edição foi realizada a IV MOMADIQ e os trabalhos foram distribuídos de acordo com as temáticas propostas na edição anterior, com a fusão de duas 
Quadro 3. Edições dos ENEQ, comissão organizadora e fomento: terceira década

\begin{tabular}{|c|c|c|}
\hline $\begin{array}{c}\text { Edição (Ano) } \\
\text { Local }\end{array}$ & Comissão Organizadora & Agências de Fomento \\
\hline $\begin{array}{l}\text { XI (2002) } \\
\text { Recife }\end{array}$ & $\begin{array}{l}\text { Rejane Martins Novais Barbosa, Maria Angela Vasconcelos de Almeida, Analice de } \\
\text { Almeida Lima, Loide Célia Brito, Angela Fernandes Campos, Arnaldo Rabelo de } \\
\text { Carvalho, Beate Saegesser Santos, Cristiano de Almeida Cardoso Marcelino Júnior, } \\
\text { Luciano de Azevedo Soares Neto, Marcelo Brito Carneiro Leão, Kátia Cristina Souza de } \\
\text { Freitas, Gilvaneide Ferreira de Oliveira e Roberto Antunes }\end{array}$ & FACEPE, CAPES, CNPq \\
\hline $\begin{array}{c}\text { XII (2004) } \\
\text { Goiânia }\end{array}$ & $\begin{array}{c}\text { Agustina Rosa Echeverría, Antônio Carlos Severo Menezes, Gerson de Souza Mól, } \\
\text { Jacqueline Maria Barbosa Vitorette, Marçal Antônio Ruggiero, Márlon Herbert Flora } \\
\text { Barbosa Soares e Wilson Botter Júnior }\end{array}$ & CNPq, CAPES \\
\hline $\begin{array}{l}\text { XIII (2006) } \\
\text { Campinas }\end{array}$ & $\begin{array}{l}\text { Adelaide Faljoni-Alário, Adriana Vitorino Rossi, Agnaldo Arroio, Camila Silveira da } \\
\text { Silva Cristina, Cristina Cimarelli Caballero Rubega, Dayse Pereira da Silva, Fábio } \\
\text { Augusto do Amaral, Gláucia Maria da Silva, Luiz Antonio Andrade de Oliveira, Luiz } \\
\text { Henrique Ferreira, José Alencar Simoni, Marcelo Giordan dos Santos, Maria Eunice } \\
\text { Ribeiro Marcondes, Maria Inês Petrucci Rosa, Maurício dos Santos Matos, Pedro da } \\
\text { Cunha Pinto Neto, Pedro Faria Filho, Regina Buffon, Salete Linhares Queiroz, Sandra } \\
\text { Boscolo Brienza, Sérgio Lontra Vieira, Simone Jaconetti Ydi e Tânia Torniziello }\end{array}$ & FAPESP, CNPq, CAPES \\
\hline $\begin{array}{l}\text { XIV (2008) } \\
\text { Curitiba }\end{array}$ & $\begin{array}{l}\text { Adriana Vitorino Rossi, Cláudio Antonio Tonegutti, Cleber Antonio Lindino, Eliane } \\
\text { Aparecida Silicz Bueno, Expedito Leite Silva, Flaveli Aparecida de Souza Almeida, } \\
\text { Flávio Massao Matsumoto, Gláucia Maria da Silva, Márlon Herbert Flora Barbosa } \\
\text { Soares, Izaura Hiroko Kuwabara, Jackson Góis, Joanez Aparecida Aires, Lenir Basso } \\
\text { Zanon, Leonora Maria Antunes Comegno, Márcia Borin da Cunha, Maria Eunice } \\
\text { Ribeiro Marcondes, Moisés Alves de Oliveira, Neide Hiroko Takada, Neide Maria } \\
\text { Michelan Kiouranis, Orliney Maciel Guimarães, Sandro Xavier de Campos, Sonia } \\
\text { Giancoli Barreto, Sonia Maria Nobre Gimenez, Soraia Freaza Lôbo }\end{array}$ & CAPES, CNPq \\
\hline $\begin{array}{l}\text { XV (2010) } \\
\text { Brasília }\end{array}$ & $\begin{array}{l}\text { Agustina Rosa Echeverría, Anna Maria Canavarro Benite, Gerson de Souza Mól, Irene } \\
\text { Cristina de Mello, Jeane Cristin Gomes Rotta, Joice de Aguiar Baptista, Maria Stela da } \\
\text { Costa Gondim, Márlon Herbert Flora Barbosa Soares, Nyuara Araújo da Silva Mesquita, } \\
\text { Patrícia Fernandes Lootens Machado, Ricardo Gauche, Roberto Ribeiro da Silva e } \\
\text { Wildson Luiz Pereira dos Santos }\end{array}$ & CAPES, CNPq \\
\hline
\end{tabular}

delas, Ensino de Química e Inclusão com Políticas Educacionais e Educação Química, em uma nova temática a Inclusão e Políticas Educacionais, além da exclusão de História e Filosofia da Química. ${ }^{4}$

O XVIII ENEQ foi realizado em 2016, na Universidade Federal de Santa Catarina (UFSC), em Florianópolis, cujo tema central foi Os desafios da formação e do trabalho do professor de química no mundo contemporâneo. $\mathrm{O}$ evento foi realizado com a colaboração e apoio de outras instituições catarinenses: Instituto Federal de Santa Catarina (IFSC); Universidade do Estado de Santa Catarina (UDESC); Instituto Estadual de Educação (IEE). ${ }^{4}$ Segundo Soares, Mesquita e Rezende, foram apresentados 1594 trabalhos. ${ }^{5}$

$\mathrm{Na} 18$. $^{\mathrm{a}}$ edição foi realizada a V MOMADIQ e os trabalhos foram distribuídos de acordo com as temáticas propostas na edição anterior. Em relação às apresentações orais dos trabalhos completos, dentre os mais de 700 trabalhos submetidos, foram designados 300 para apresentação em sessão coordenada. ${ }^{4}$ Nessa edição foram fornecidas informações mais detalhadas sobre o processo de avaliação dos trabalhos. De forma inédita, além dos professores universitários e pesquisadores, o corpo de avaliadores (em torno de 300) contou com a colaboração de doutorandos da área de Educação em Ciências. ${ }^{12,13} \mathrm{Na}$ assembleia final foi registrada a aprovação de uma nova entidade dos educadores químicos brasileiros, com aprovação de uma Comissão Nacional Provisória (CNP), incumbida de tratar de assuntos que permitiriam a sua viabilização. ${ }^{12,13}$

O XIX ENEQ foi realizado em 2018, na Universidade Federal do Acre (UFAC), em Rio Branco, e teve como tema Docência em química: transformações e mudanças no contexto educacional contemporâneo. O tema surgiu da inspiração nos grandes rios que circundam o estado do Acre, descritos como agentes de transformação. Segundo Porto e Queiroz, foram apresentados 416 trabalhos. ${ }^{14,15} \mathrm{~A}$ inovação ocorrida nessa edição foi a proposição da sessão Experiências da Licenciatura em Foco, na qual os participantes do evento discutiram práticas docentes ou relatos de experiências sobre assuntos voltados ao ensino de química, vivenciadas nos cursos de Licenciatura e nas escolas de Educação Básica. ${ }^{4}$ Assim como realizado no XVII ENEQ, trabalhos apresentados no evento foram, novamente, selecionados e publicados na QNEsc, distribuídos em dois volumes. ${ }^{14,15}$

$\mathrm{Na}$ assembleia de encerramento, a CNP da Associação de Educadores Químicos, instituída na edição anterior, outorgou uma nova entidade, a Sociedade Brasileira de Ensino de Química (SBEnQ), originando um legado aos que atuam e lutam pela valorização do ensino e da docência em química no país. Além disso, foram aprovados: o Estatuto da SBEnQ; a composição da primeira diretoria; os membros honorários da SBEnQ; os representantes regionais; o conselho consultivo nacional; o conselho fiscal; o valor de anuidade. ${ }^{14,15}$

O Quadro 4 ilustra a distribuição dos ENEQ por edição (ano), local, comissão organizadora e agências de fomento, durante a quarta década. Os anais do evento foram disponibilizados na internet por meio dos sites das respectivas instituições realizadoras.

No período em questão, os eventos contaram com apoio institucional das universidades sede dos encontros e da Divisão de Ensino da Sociedade Brasileira de Química, além do apoio do CRQ, presente em duas edições, assim como de editoras e livrarias, dentre outros segmentos comerciais. Em relação às agências de fomento, a CAPES apoiou todas as edições e o CNPq esteve presente somente na $16 .^{\mathrm{a}}$ edição, assim como a Fundação de Amparo à Pesquisa do Estado da Bahia (FAPESB).

Com base nas informações até aqui apresentadas, são estabelecidas, a seguir, relações entre alguns dos acontecimentos observados nos ENEQ e a consolidação da área de Educação em Química no país. Tais relações foram construídas a partir de indicadores, apontados por Taber, ${ }^{16}$ pautado no trabalho de Fensham, ${ }^{17}$ que podem ser usados 
Quadro 4. Edições dos ENEQ, comissão organizadora e fomento: quarta década

\begin{tabular}{|c|c|c|}
\hline $\begin{array}{c}\text { Edição (Ano) } \\
\text { Local }\end{array}$ & Comissão Organizadora & Agências de Fomento \\
\hline $\begin{array}{l}\text { XVI (2012) } \\
\text { Salvador }\end{array}$ & $\begin{array}{c}\text { Abraão Felix da Penha, Alcione Torres Ribeiro, Bárbara Cristina Tavares Moreira, } \\
\text { Bruno Ferreira dos Santos, Carlos Correia de Souza, Carmen Silvia da Silva Sá, Edilson } \\
\text { Fortuna de Moradillo, Erivanildo Lopes da Silva, Elisa Prestes Massena, Fábio Adriano } \\
\text { Santos da Silva, Hélio Oliveira Pimentel, Isadora Melo Gonzalez, Ivete Maria dos } \\
\text { Santos, Jailson Alves dos Santos, Joelma Cerqueira Fadigas, José Luis de Paula Barros } \\
\text { Silva, Lailton Passos Cortes Júnior, Luciana Passos Sá, Maria Bernadete de Melo } \\
\text { Cunha, Nelson Rui Ribas Bejarano, Neurivaldo José de Guzzi Filho, Ródnei Almeida } \\
\text { Souza, Solange Menêzes de Sousa Villa, Soraia Freaza Lôbo, Tatiana do Amaral Varjão } \\
\text { e Tereza Simonne Mascarenhas Santos }\end{array}$ & FAPESB, CAPES, CNPq \\
\hline $\begin{array}{l}\text { XVII (2014) } \\
\text { Ouro Preto }\end{array}$ & $\begin{array}{c}\text { Gilmar Pereira de Souza, Diego Luiz Nunes Ventrella, Paula Cristina Cardoso } \\
\text { Mendonça, Aparecida Barbosa Mageste, Nilmara Braga Mozzer, Clarissa Rodrigues, } \\
\text { Ângela Leão Andrade, Cláudio Gouvêa dos Santos, Fabiana Aparecida Lobo, Humberto } \\
\text { Vieira Fajardo, Mauricio Xavier Coutrim, Roberta Eliane Santos Froes-Silva e Marcelo } \\
\text { Gomes Speziali }\end{array}$ & CAPES \\
\hline $\begin{array}{l}\text { XVIII (2016) } \\
\text { Florianópolis }\end{array}$ & $\begin{array}{c}\text { Aldo Sena de Oliveira, Ana Carolina Koentopp, Anelise Maria Regiani, Berenice da } \\
\text { Silva Junkes, Carlos Alberto Marques, Dilma Maria de Oliveira, Éder da Silva e Sá, } \\
\text { Eduardo Antônio Zampiron, Franciani Becker Roloff, José Carlos Gesser, Lidiane } \\
\text { Meier, Maria da Graça Moraes Braga Martin, Renata Pietsch Ribeiro, Talles Viana } \\
\text { Demos e Wesley Alexandre Saade }\end{array}$ & CAPES \\
\hline $\begin{array}{l}\text { XIX (2018) } \\
\text { Rio Branco }\end{array}$ & $\begin{array}{c}\text { Adriano Antonio Silva, Gahelyka Aghta Pantano Souza, Ilmar Bernardo Graebner, } \\
\text { Elisângela Maria de Souza Anastácio, Aline Andréia Nicolli, Danielly de Souza Nóbrega } \\
\text { e Danielly Franco de Matos }\end{array}$ & CAPES \\
\hline
\end{tabular}

para fornecer indícios sobre a consolidação de uma área acadêmica. O delineamento de uma linha do tempo (Figura 1), com a distribuição de alguns dos acontecimentos, permite uma melhor compreensão do estabelecimento das relações.

Segundo Taber, ${ }^{16}$ são os seguintes os indicadores que podem ser considerados na avaliação da extensão da consolidação de uma área acadêmica: realização de eventos, de caráter regular, vinculados a assuntos específicos da área, publicação de revistas e produção de material didático relacionado a ela e existência de profissionais que aí atuam.

O primeiro indicador ao qual nos remetemos é a realização de eventos, de caráter regular, vinculados a assuntos específicos da área. ${ }^{16}$ As edições do ENEQ, aqui descritas de forma sucinta, contemplam amplamente este indicador. De fato, o evento, que na sua primeira edição, ainda em 1982 (Figura 1, cor azul, linha superior), havia ocorrido como satélite da RASBQ e da Reunião Anual da SBPC, permaneceu nessa condição, com relação ao evento da RASB, até 1988 (Figura 1, cor azul, linha inferior), e ao da SBPC, até o início da sua segunda década, em 1992. Em contraponto, a partir da edição de 1994, o próprio ENEQ passou a assumir um tema central (Figura 1, cor vermelha, linha superior) e a ser acompanhado por outros eventos, mais alinhados com os seus objetivos, como o ESEQ, ECODEQ, EDEQ, ECOQ, SIMPEQ, EPPEQ, em quase todas as edições, evidenciando o seu caráter agregador. Caráter esse que é claramente traduzido no número crescente de participantes e de trabalhos apresentados ao longo dos anos. De fato, a título de exemplo, e segundo consta em Editorial da QNEsc de 2016, ${ }^{13}$ a edição do mesmo ano do evento "contou com 2614 inscritos, sendo 1488 estudantes de graduação, 385 estudantes de pós-graduação, 440 professores da educação básica e 301 professores de educação superior. O número de trabalhos aceitos chegou a 1500, superando os 1066 do evento anterior" (p. 199). ${ }^{13}$

A maneira de organização dos eventos também fornece indícios sobre a consolidação da área a qual se vinculam, sendo usual que

\section{Encontro Nacional de Ensino de Química- ENEQ}

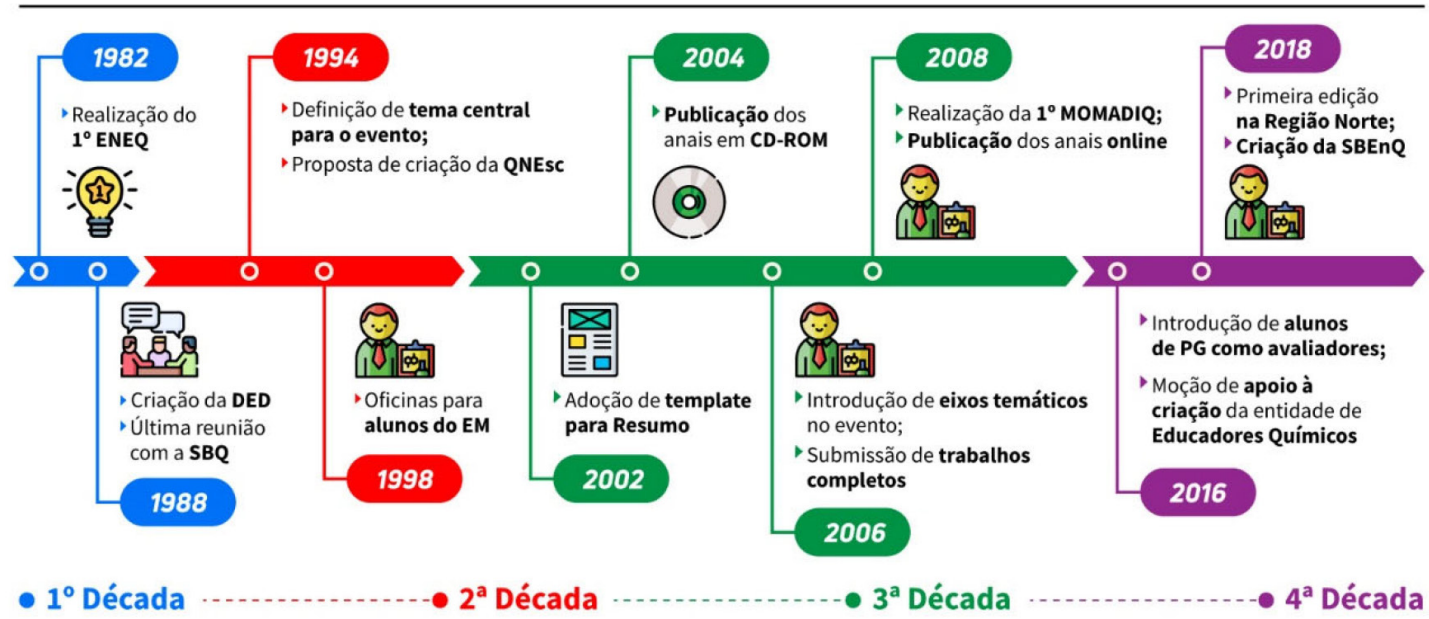

Figura 1. Linha do tempo de acontecimentos nos ENEQ, no período de 1982 a 2018 
comunidades em expansão lancem mão da padronização na forma de apresentação dos trabalhos e da especialização, uma vez que precisam lidar com um grande número de informaçõos disponíveis. ${ }^{18}$ Ambos os movimentos, de padronização e especialização, foram realizados no início da década de 2000 nos ENEQ. Com efeito, em 2002, os participantes foram solicitados a redigir os trabalhos de modo a que seguissem um padrão (Figura 1, cor verde, linha inferior), com apresentação de tópicos definidos a priori. Duas edições após esta, no aniversário de 25 anos do ENEQ, em 2006, a delimitação dos trabalhos em áreas temáticas foi estabelecida e a opção por apresentação de resumo ou trabalho completo oferecida (Figura 1, cor verde, linha inferior).

Também como consequência da expansão e renome do evento, a quantidade de instituições envolvidas na organização e o apoio de agências de fomento foram, quase que invariavelmente, se avolumando e diversificando ao longo do tempo (com aportes financeiros não somente do governo federal, mas também de governos estaduais e participação de organizadores não só de instituições públicas) e os anais do evento foram progressivamente alterados, passando da forma impressa ao CD-ROM e disponibilização na internet (Figura 1, cor verde, linha superior). Ainda com relação à organização do evento, por um período longo, os ENEQ foram "de alguma maneira, apoiados ou chancelados pela DED, seja no que se refere a passagens de convidados ou, ainda, apoio logísitico" (p. 656). Observa-se uma alteração, em 2018, na perspectiva da colaboração da Divisão de Ensino da Sociedade Brasileira de Química (Figura 1, cor azul, linha inferior) aos ENEQ, com a criação da SBEnQ (Figura 1 , cor roxa, linha superior), que passa a responsabilizar-se pela sua organização nas próximas edições. Essa transição na natureza da organização consiste em indicador relevante da consolidação da área de Educação em Química.

O segundo indicador é a publicação de revistas epecíficas da área. ${ }^{16} \mathrm{~A}$ proposta de criação de uma revista que abordasse o ensino de química, formulada no ENEQ de 1994 (Figura 1, cor vermelha, linha superior), culminou com o lançamento da QNEsc, em maio de $1995 .{ }^{8}$ A sua evolução oferece elementos para que se possa afirmar que este indicador é também sobejamente contemplado. Apontada por Ramos, Massena e Marques ${ }^{8}$ como um "patrimônio dos educadores químicos" (p.116), ${ }^{8}$ a revista está vinculada à Divisão de Ensino da Sociedade Brasileira de Química desde a sua criação e desenvolve ações no âmbito dos ENEQ, inclusive a partir da seleção e publicação de trabalhos apresentados no evento, como verificado nas edições de 2014 e 2018

O terceiro indicador tem estreita relação com a produção de materiais didáticos relacionados à área. ${ }^{16} \mathrm{~A}$ relevância que estes assumem na área de Educação em Química é evidenciada nos ENEQ a partir de 2008, com a realização do I MOMADIQ (Figura 1, cor verde, linha superior), quando foram apresentados dezenove materiais didáticos variados, ${ }^{19}$ incluindo os livros Química e sociedade, de autoria de Wildson Luiz Pereira, Gerson de Souza Mól e colaboradores, e Práticas pedagógicas para o ensino médio, de autoria de Maira Ferreira, Lavínia Morais, Tatiana Zarichta Nichele e José Cláudio Del Pino. Nos eventos posteriores, a sessão dedicada a materiais didáticos foi mantida e recebeu maior número de contribuições. Em 2016, por exemplo, ela foi composta por 75 trabalhos,${ }^{20}$ corroborando o atendimento deste indicador. Com efeito, a necessidade de criação do MOMADIQ nos ENEQ já aponta para o seu atendimento, pois veio ao encontro de um anseio da comunidade pela divulgação de materiais didáticos produzidos nos grupos de pesquisa e que, por falta de divulgação ampla, ficavam restritos ao local e imediações de onde foram criados.

$\mathrm{O}$ quarto indicador tem estreita relação com a atuação de profissionais na área. ${ }^{16}$ Novamente, as edições do ENEQ aqui descritas reforçam o atendimento ao referido indicador, a julgar pela composição das comissões organizadoras ao longo do tempo. Na primeira década o número de membros varia entre cinco e sete, sendo todos vinculados às instituições do Sul e do Sudeste do Brasil. Embora na segunda década esse número ainda se mantenha restrito, não ultrapassando uma dezena, observa-se que as comissões passam a contar com participantes de cada um dos locais que abrigam o evento, fornecendo indícios sobre a disseminação de profissinais atuantes na área de Educação em Química também nas regiões Nordeste e CentroOeste. Essa tendência é mantida nas duas décadas seguintes, sendo que no ENEQ de 2018, na década mais recente, finalmente celebrado na região Norte (Figura 1, cor roxa, linha superior), é corroborada a presença também aí de profissionais envolvidos com a área.

$\mathrm{O}$ número de membros das comissões organizadoras também cresce a partir da terceira década, na maioria das edições, para atender a uma demanda de participantes que se eleva. A observação da recorrência de docentes que colaboram com as comissões, pelo menos duas vezes, ao longo do tempo investigado neste manuscrito, sugere o engajamento expressivo dos mesmos na área, auxiliando na sua consolidação. O maior número de participações nas comissões organizadoras é creditado à Maria Eunice Ribeiro Marcondes, sendo quatro na primeira década, uma na segunda e duas na terceira, seguida por Roseli Pacheco Schnetzler, com três participações na primeira década e uma na segunda. Na primeira década nota-se também a participação em duas edições de Angélica Ambrogi e Júlio Cezar Foschini Lisbôa, que, juntamente com Maria Eunice Ribeiro Marcondes e Roseli Pacheco Schnetzler, constituem um grupo que reune experiência no quesito "elaboração dos ENEQ", subsidiando a promoção do evento.

Maurivan Güntzel Ramos e Luiz Otávio Fagundes Amaral participam duas vezes da organização dos ENEQ no período que abarca a primeira e segunda década e reforçam o grupo mencionado acima. Cabe destacar que a atuação de todos os citados, com exceção de Maurivan (região Sul), ocorre na região Sudeste, o que indica uma concentração inicial de docentes dedicados à área de Educação em Química nesta região, com posterior disseminação para as demais. Tal assertiva é confirmada a partir da observação, nas décadas seguintes, de recorrência de participação de Gerson de Souza Mól (três edições), Agustina Rosa Echeverría (duas edições) e Márlon Herbert Flora Barbosa Soares (três edições) nas comissões organizadoras, sendo todos atuantes na região Centro-Oeste. Na região Nordeste, observa-se a participação em duas comissões de Soraia Freaza Lôbo. Da mesma forma, Adriana Vitorino Rossi e Gláucia Maria da Silva, ambas da região Sudeste, também colaboraram em duas comissões.

Uma vez constatada a disseminação pelo país de atuantes na área, o perfil dessa comunidade recebe investigação mais aprofundada, realizada considerando a autoria dos trabalhos apresentados no evento. Tal aspecto será discutido no tópico a seguir, podendo fornecer mais indícios sobre o atendimento do indicador em questão. Cabe ainda reforçar que a criação da SBEnQ (Figura 1, cor roxa, linha superior), em 2018, e a introdução de alunos de pós-graduação como avaliadores no evento de 2016 (Figura 1, cor roxa, linha inferior) também corroboram a contemplação desse último indicador, pois representam a existência de um coletivo especializado de pessoas ligadas ao ensino e à pesquisa na área.

\section{AUTORIA NOS ENEQ (1982 A 2010)}

No presente tópico são apresentados os resultados decorrentes das análises da produção dos anais do ENEQ, durante o período de 1982 a 2010, de acordo com o perfil de autores. Esta foi realizada considerando o montante de 2552 trabalhos. A distribuição dos documentos para cada edição do evento está representada na Figura 2. 


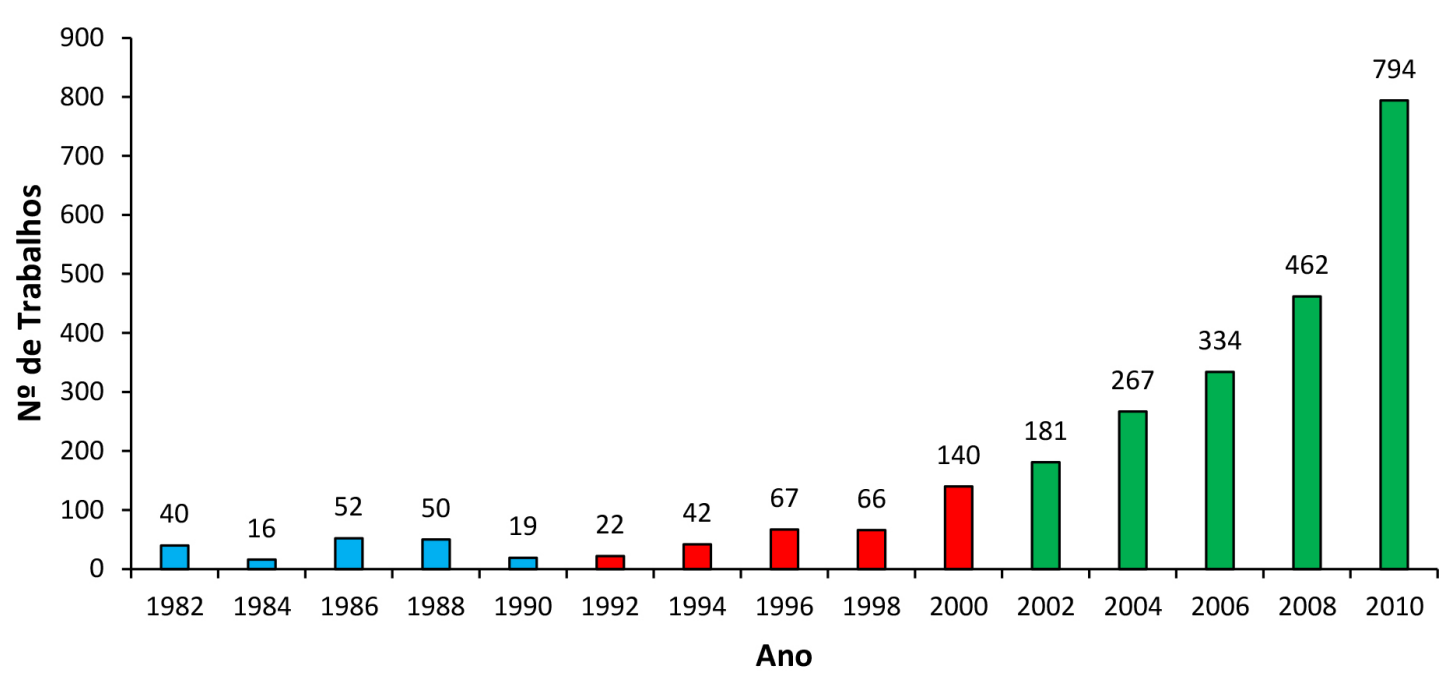

Figura 2. Distribuição do número de trabalhos apresentados nos ENEQ, de acordo com o ano do evento

A Figura 2 ilustra a evolução da produção ao longo do tempo, com 40 trabalhos em 1982, alcançando 794 trabalhos em 2010. A produção na primeira década foi irregular, na segunda ocorreu um aumento gradual e na terceira uma vigorosa ascendência foi observada. Para cada uma delas foi investigado o número de trabalhos produzidos por cada autor. Em seguida, as nuvens de palavras foram geradas com os sobrenomes dos autores, seguidos das iniciais dos nomes.
Por exemplo, a indicação de 'mortimeref' está associada ao autor Eduardo Fleury Mortimer.

O Quadro 5 apresenta as nuvens de palavras com a distribuição dos nomes dos autores com produção mais numerosa entre a primeira e a terceira década dos ENEQ. Constam na primeira década nomes de autores que apresentaram quatro trabalhos ou mais; na segunda, seis trabalhos ou mais; e vinte trabalhos ou mais na terceira década.

Quadro 5. Nuvens de tags com sobrenome e iniciais dos nomes dos autores e número de trabalhos (1982-2010)

amarallof(5) chassotai(5) dominguezSf(7) hartwigdr(4) jucamew(5) justirs(4) marcondesmer(6) matosjamg(4) mortimeref(5) osoriovkl(4) rochafilhorc(6) romanellili(4) schnetzlerrp(5) silvarr(4) Zuninoav(5)

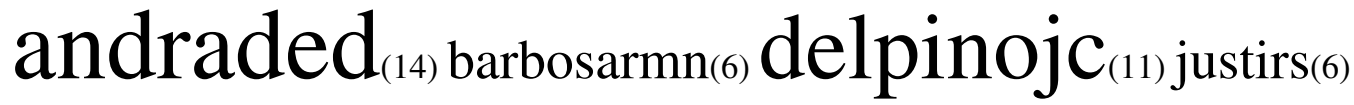
lealmc ${ }_{(8)} \operatorname{limaps}(6) \operatorname{machadoah}_{(9)} \operatorname{marcondesmer}_{(8)}$ mortimeref $_{(8)}$ ritatg $_{(9)}$ schmitzlc(6) $_{(\text {schnetzlerrp(6) }}$ teixeiraamrf $f_{(9)}$ vieirala(6) silvajlpb(6) $_{(0)}$ $\operatorname{araujosscm}_{(27)}$ arroioa $_{(24)}$ field'skap ${ }_{(34)}$ ferreiralh $_{(30)}$ freitasfilhojr $_{(25)}$ giordanm $_{(22)}$ justirs(21) lauxenaa ${ }_{(24)}$ leaombc $_{(26)}$ marquesal (22) $_{\text {marquesrn(21) }}$ misturacm(24) marcondesmer $_{(45) \text { molgs }(20)}$ nunessmt $_{233}$ oliveiralaa $_{277}$ quadrosal $l_{\otimes}$ queirozsl $l_{2 \infty}$ Soaresmhfb 
Associado ao nome de cada autor está o número de trabalhos apresentado nos ENEQ no período em foco.

Todas as informações, mencionadas a seguir, sobre as publicações e orientações de pós-graduação foram extraídas do Currículo Lattes de cada um dos autores, cujos nomes estão nas nuvens de tags, em 30 de março de 2021.

\section{Primeira década}

Conforme ilustra o Quadro 5, na primeira década destacaramse quinze autores $(\mathrm{n} \geq 4$, o que corresponde a aproximadamente 2,2\% da produção), a saber: Sérvulo Folgueras Domínguez, com sete trabalhos, Maria Eunice Ribeiro Marcondes e Romeu Cardozo Rocha-Filho, cada um com seis trabalhos; Attico Inacio Chassot, Luiz Otávio Fagundes Amaral, Maria Ester Weyne Jucá, Eduardo Fleury Mortimer, Roseli Pacheco Schnetzler e André Valdir Zunino, cada um com cinco trabalhos; Dácio Rodney Hartwig, Rosária da Silva Justi, João Augusto de Mello Gouveia Matos, Viktoria Klara Lakatos Osório, Lilavate Izapovitz Romanelli, Roberto Ribeiro da Silva, cada um com quatro trabalhos.

Alguns dos autores citados tiveram grande expressão na primeira década, liderando ou participando de iniciativas que se mostraram valiosas para o desabrochar da área de Educação em Química. Dentre os que apresentaram o maior número de trabalho, Sérvulo Folgueras Domínguez e Romeu Cardozo Rocha-Filho possuem em comum o fato de terem publicado livros de caráter didático, no período que antecede a primeira década ou na própria. Sérvulo Folgueras Domínguez publicou As experiências em química, ${ }^{21}$ Classificação periódica dos elementos, ${ }^{22}$ Reações químicas, ${ }^{23} \mathrm{e}$ Orbitais - estrutura de átomos, moléculas e cristais, ${ }^{24}$ enquanto Romeu Cardozo Rocha-Filho publicou os livros Grandezas e unidades de medida: o sistema internacional de unidades ${ }^{25} \mathrm{e}$ Introdução à química experimental. ${ }^{26}$ Romeu Cardozo RochaFilho publicou ainda uma série de trabalhos na primeira década relacionados ao ensino de química, distribuídos nas revistas Química Nova (mais de uma dezena), Ciência e Cultura (cinco artigos) e Journal of Chemical Education (cinco artigos).

Maria Eunice Ribeiro Marcondes participou da comissão organizadora de quatro edições do ENEQ na primeira década, conforme mencionado anteriormente. A sua produção referente à área, na primeira década, ou no período que a antecede, inclui o artigo publicado na revista Ciência e Cultura: Sugestões para a formação de professores da área científica para as escolas de $1^{\circ}$ e $2^{\circ}$ graus,,$^{27}$ além do volume III dos Subsídios para a implementação do guia curricular de química para o $2^{\circ}$ grau. ${ }^{28}$ Segundo Sicca, ${ }^{29}$ os Subsídios consistiam em coletânea de atividades práticas de laboratório, planejadas para serem executadas nos laboratórios das escolas, sendo distribuídos para professores.

Attico Inacio Chassot junta-se ao rol de autores que produziram livros na primeira década, tendo publicado $A$ educação no ensino de química (coleção ensino de $2^{\circ}$ grau). ${ }^{30}$ Além disso, como mencionado, ele foi o organizador do Primeiro EDEQ, em 1980, no Rio Grande do Sul, encontro este que impulsionou a realização do ENEQ em 1982. ${ }^{3}$

Ainda dentre os autores que se destacaram na primeira década, Roseli Pacheco Schnetzler foi a única que concluiu o doutorado no exterior, em Educação Química, no período em questão, sob a supervisão de Malcom Frazer, conferencista da abertura do I ENEQ. ${ }^{3}$ A tese, A method for representing and comparing content and cognitive structures ${ }^{31}$ foi defendida em 1987 na Universidade de East Anglia. A sua participação na comissão organizadora do ENEQ, conforme mencionado anteriormente, ocorreu em três edições na primeira década, intervalo no qual também publicou um artigo que versa sobre o SPEC. ${ }^{32} \mathrm{O}$ pioneirismo de Schnetzler na área de
Educação em Química também é constatado em uma orientação de dissertação de mestrado sobre a temática, ainda em 1989, intitulada Aprendizagem em química: parâmetros de significação $e$ de investigação no ensino de $2^{\circ}$ grau - um estudo de material instrucional do PROQUIM. ${ }^{33}$

Roberto Ribeiro da Silva publicou em parceira com Romeu Cardozo Rocha-Filho o livro Introdução à química experimental, ${ }^{26}$ citado anteriormente. Ambos também são autores de uma série de artigos publicados durante a primeira década, nas revistas Química Nova e Ciência e Cultura, sobre temáticas vinculadas ao ensino de química. A título de exemplo, citamos a série: Uma metodologia para levantamento e análise de disciplinas experimentais de química. I. Habilidades experimentais, ${ }^{34}$ Uma metodologia para levantamento e análise de disciplinas experimentais de química. II. Análise dos conteúdos de disciplinas das áreas de química inorgânica e orgânica, ${ }^{35}$ Uma metodologia para levantamento e análise de disciplinas experimentais de química. III. Análise dos conteúdos das áreas de química analítica, físico-química e química geral. ${ }^{36}$

Dácio Rodney Hartwig publicou em parceira com Romeu Cardozo Rocha-Filho uma série de artigos sobre temáticas vinculadas ao ensino de química nas revistas Química Nova e Journal of Chemical Education. A título de exemplo, citamos: Experiências e analogias simples para o ensino de conceitos em química: pressão de vapor de líquidos, ${ }^{37}$ A visual analogy for metallic deposition, ${ }^{38}$ Uma aproximação alternativa ao ensino de misturas líquidas binárias ideais. ${ }^{39}$ Também na primeira década, Dácio Rodney Hartwig foi autor do seguinte artigo, publicado em parceria com Sérvulo Folgueras Domínguez: Equilibração entre os aspectos qualitativos e quantitativos no ensino de química ${ }^{40}$

Eduardo Fleury Mortimer e Rosária da Silva Justi iniciam a sua trajetória como pesquisadores na primeira década, tendo obtido os títulos de mestre em 1988 e em 1991, respectivamente.

Com relação às instituições de origem dos autores, verifica-se presença marcante da Universidade Federal de São Carlos (UFSCar) e da UFMG, instituições sede de quatro dos quinze autores. No caso da UFSCar, são os seguintes: Sérvulo Folgueras Domínguez, Romeu Cardozo Rocha-Filho, Dácio Rodney Hartwig e Roberto Ribeiro da Silva. No caso da UFMG, são os seguintes: Luiz Otávio Fagundes do Amaral, Eduardo Fleury Mortimer, Rosária da Silva Justi e Lilavate Izapovitz Romanelli.

\section{Segunda década}

No que tange à segunda década, conforme ilustra o Quadro 5, destacaram-se quinze autores $(n \geq 6$, o que corresponde a aproximadamente 1,8\% da produção), a saber: Djalma Andrade, com catorze trabalhos; José Cláudio Del Pino, com onze trabalhos; Andréa Horta Machado, Tânia Guimarães Santa-Rita e Ana Maria Rangel de Figueiredo Teixeira, cada uma com nove trabalhos; Murilo Cruz Leal, Maria Eunice Ribeiro Marcondes e Eduardo Fleury Mortimer, cada um com oito trabalhos; Rejane Martins Novais Barbosa, Rosária da Silva Justi, Patrícia Soares de Lima, Luiz Carlos Schmitz, Roseli Pacheco Schnetzler, José Luis de Paula Barros Silva e Luciana Augusta Vieira, cada um com seis trabalhos.

Dentre os autores com maior produção na segunda década, quatro já estavam em posição de destaque na primeira década: Maria Eunice Ribeiro Marcondes, Eduardo Fleury Mortimer, Roseli Pacheco Schnetzler e Rosária da Silva Justi. Em contraponto, autores com produção de livros de caráter didático e/ou de artigos sobre o ensino de química, como Sérvulo Folgueras Domínguez, Romeu Cardozo Rocha-Filho, Attico Inacio Chassot e Dácio Rodney Hartwig, não mais se destacam no cenário dos ENEQ, considerando o critério adotado para a construção das nuvem de tag desse período. A ausência 
de protagonismo no evento, no entanto, não caracteriza a interrupção de dedicação à temática por parte de nenhum deles.

De fato, no caso de Romeu Cardozo Rocha-Filho, a publicação de um artigo no Journal of Chemical Education e mais de uma dezena de artigos na QNEsc, dentre outros de mesmo caráter, além da produção dos livros $O$ azul do planeta: um retrato da atmosfera terrestre ${ }^{41}$ e Introdução aos cálculos da química, ${ }^{42}$ indicam a relevância das suas contribuições para a área de Educação em Química na segunda década. Attico Inacio Chassot também segue essa mesma tendência, com a publicação de mais de três dezenas de artigos relacionados ao ensino de química, oito deles na QNEsc, além da produção de livros, como: Catalisando transformações na educação, ${ }^{43}$ e Ciência, ética e cultura na educação. ${ }^{44}$ Da mesma forma, Dácio Rodney Hartwig publicou dois artigos na QNEsc e um na Química Nova, além de livros didáticos nas áreas de Química Inorgânica, ${ }^{45}$ Físico-Química ${ }^{46}$ e Química Orgânica ${ }^{47}$ Sérvulo Folgueras Domínguez publica o livro Metodologia e prática de ensino de química. ${ }^{48}$

Roberto Ribeiro da Silva também junta-se aos autores acima mencionados, tendo publicado mais de uma dezena de artigos sobre a temática em questão, quatro na QNEsc e igual número na Química Nova, além dos livros, mencionados anteriormente, Introdução aos cálculos da química ${ }^{42}$ e $O$ azul do planeta: um retrato da atmosfera terrestre ${ }^{41}$ ambos em parceria com Romeu Cardozo Rocha-Filho. O livro Química na sociedade: projeto de ensino de química em um contexto social, ${ }^{49}$ também é de sua coautoria.

Os autores que mantiveram a posição de destaque também na segunda década consolidam a sua atuação no âmbito da área de Educação em Química. Maria Eunice Ribeiro Marcondes intensificou a produção de artigos frente à primeira década, com dois deles publicados na QNEsc e dois na Química Nova, além de apresentar coautoria na coleção de livros Interações e transformações, volumes I a III. ${ }^{50-52} \mathrm{Na}$ mesma perspectiva, Roseli Pacheco Schnetzler, que havia publicado um único artigo na primeira década, aumentou a produção, com três deles presentes na QNEsc. Além disso, orientou teses de doutorado e dissertações de mestrado, tendo uma delas originado o livro Educação em química: compromisso com a cidadania, ${ }^{53}$ em parceria com Wildson Luiz Pereira dos Santos, que se encontra atualmente na quarta edição.

As trajetórias de Eduardo Fleury Mortimer e Rosária da Silva Justi ganham impulso com a conclusão do doutorado em 1994 e 1997 , respectivamente. Ambos vivenciaram, no período, experiências de pesquisa no exterior, com o primeiro sob a supervisão de Rosalind Driver, e a segunda sob a supervisão de John Kenward Gilbert. Enquanto na primeira década foi publicado um único artigo por Eduardo Fleury Mortimer, na segunda o número ultrapassa duas dezenas, sendo seis na QNEsc e quatro na Química Nova. Rosária da Silva Justi, sem publicação de artigo na primeira década, teve seis publicados na segunda, dois deles na QNEsc, além de ter produzido o livro Aprendendo química,${ }^{54}$ em parceria com Lilavate Izapovitz Romanelli. A orientação de dissertações de mestrado foi concluída por Eduardo Fleury Mortimer, assim como a produção de livros, sendo Linguagem e formação de conceitos no ensino de ciências ${ }^{55}$ amplamente divulgado na comunidade de educadores químicos.

José Cláudio Del Pino (UFRGS), José Luis de Paula Barros Silva (UFBA), Djalma Andrade (UFS) e Rejane Martins Novais Barbosa (UFRPE) estão entre os autores que não haviam recebido destaque na primeira década e que despontam na segunda como lideranças nos suas respectivas regiões de origem. José Cláudio Del Pino é um dos fundadores do grupo Área de Educação Química da UFRGS, criado em 1989. No período em questão, publicou mais de uma dezena de artigos, sendo dois na QNEsc e um na Química Nova.

Rejane Martins Novais Barbosa publicou quatro artigos na segunda década, um deles na QNEsc. Assim como Eduardo Fleury
Mortimer e Rosária da Silva Justi, Rejane Martins Novais Barbosa realizou parte da sua formação no exterior, obtendo o título de doutora em 1996, sob a supervisão de Roger Maskill. Já Andréa Horta Machado, vinculada à UFMG, publicou oito artigos no período, cinco deles na QNEsc. A sua parceria com Eduardo Fleury Mortimer desponta com a publicação de três artigos.

Murilo Cruz Leal, vinculado à Universidade Federal de São João Del Rei (UFSJ), publicou quatro artigos no período e iniciou o seu doutorado, sob a supervisão de Eduardo Fleury Mortimer, em 1999. Nessa perspectiva, verifica-se, na passagem da primeira para a segunda década, a influência positiva da formação de formadores na constituição da área de Educação em Química.

Com relação às instituições de origem dos autores, enquanto a UFSCar perde seu destaque, continua marcante a presença da UFMG, instituição sede de três, dentre os quinze autores: Rosária da Silva Justi, Andréa Horta Machado e Eduardo Fleury Mortimer.

\section{Terceira década}

No que tange à terceira década, conforme ilustra o Quadro 5, foram destacados dezenove autores $(n \geq 20$, o que corresponde a aproximadamente 1,0\% da produção), a saber: Márlon Herbert Flora Barbosa Soares, com 54 trabalhos; Maria Eunice Ribeiro Marcondes, com 45 trabalhos; Karla Amâncio Pinto Field's, com 34 trabalhos; Ana Luiza de Quadros, com 33 trabalhos; Luiz Henrique Ferreira, com 30 trabalhos; Luiz Antônio Andrade de Oliveira e Sandra Cristina Marquez Araújo, cada um com 27 trabalhos; Marcelo Brito Carneiro Leão, com 26 trabalhos; João Rufino de Freitas Filho, com 25 trabalhos; Agnaldo Arroio, Ademar Antonio Lauxen, Clóvia Marozzin Mistura e Salete Linhares Queiroz, cada um com 24 trabalhos; Simara Maria Tavares Nunes, com 23 trabalhos; André Luis Marques e Marcelo Giordan, cada um com 22 trabalhos; Rosebelly Nunes Marques e Rosária da Silva Justi, cada uma com 21 trabalhos; Gerson de Souza Mól, com 20 trabalhos.

Dentre os autores com maior produção na terceira década, dois já estavam em posição de destaque na primeira e na segunda década: Maria Eunice Ribeiro Marcondes e Rosária da Silva Justi. A trajetória de ambas se consolida ainda mais neste período, com a publicação, por Maria Eunice Ribeiro Marcondes, de mais de duas dezenas de artigos, sete deles na QNEsc, além de supervisões de mestrado e de doutorado. Rosária da Silva Justi também publicou mais de duas dezenas de artigos, dois deles na QNEsc, e supervisionou dissertações de mestrado e tese de doutorado.

Assim como observado entre a primeira e a segunda década, a redução ou a ausência de apresentação de trabalhos nos ENEQ na terceira década não caracteriza a interrupção de dedicação à temática por parte de pesquisadores de maior expressão na segunda década, como Roseli Pacheco Schnetzler, Eduardo Fleury Mortimer, Andréa Horta Machado, José Cláudio Del Pino, José Luis de Paula Barros Silva e Rejane Maria Novais Barbosa.

Roseli Pacheco Schnetzler continuou contribuindo com a área, publicando uma dezena de artigos e o livro intitulado Orientadores em foco: o processo da orientação de teses e dissertações em educação, ${ }^{56}$ além da supervisão de dissertações de mestrado e teses de doutorado.

Eduardo Fleury Mortimer permaneceu com forte atuação na área, com a publicação de mais de três dezenas de artigos, sendo três na QNEsc; sete livros, sendo dois em língua estrangeira: Meaning making in secondary science classroom ${ }^{57} \mathrm{e}$ o Lenguaje y formación de conceptos en la enseñaza de las ciencias,${ }^{58}$ e livros didáticos, com coautoria de Andréa Horta Machado. ${ }^{59}$ Além disso, supervisionou dissertações de mestrado e teses de doutorado. Da mesma forma, Andréa Horta Machado publicou dois artigos na QNEsc e também supervisionou uma dissertação de mestrado. 
José Cláudio Del Pino, embora não tenha alcançado, na terceira década, produção de destaque no ENEQ, segundo os critérios para a construção da nuvem exibida no Quadro 5, trouxe contribuições numerosas e significativas para a área. De fato, José Cláudio Del Pino publicou mais de oito dezenas de artigos, sendo cinco na QNEsc e realizou a supervisão de dissertações de mestrado e teses de doutorado. Similarmente, José Luis de Paula Barros Silva, publicou artigos tanto na Química Nova quanto na QNEsc e orientou dissertações de mestrado e tese de doutorado. Rejane Martins Novais Barbosa, por sua vez, publicou mais de uma dezena de artigos no período, três deles na QNEsc, e supervisionou dissertações de mestrado.

Durante a terceira década, um amplo rol de autores se junta àqueles de maior expressão na segunda década, dentre os quais estão os que foram orientandos de mestrado ou doutorado de Eduardo Fleury Mortimer, Roberto Ribeiro da Silva e José Cláudio Del Pino. É o caso, respectivamente, de Ana Luiza de Quadros, com supervisão de doutorado por parte do primeiro, e produção no período de mais de duas dezenas de artigos, cinco deles na QNEsc, e um livro intitulado Introdução a química. ${ }^{60}$ Da mesma forma, Gerson de Souza Mól, com supervisão de doutorado por parte de Roberto Ribeiro da Silva, publicou mais de uma dezena de artigos, sete deles na QNEsc, livros didáticos, com destaque para Química \& sociedade, ${ }^{61}$ e orientação de dissertações de mestrado. Já Ademar Antonio Lauxen, que foi orientado por José Cláudio Del Pino, publicou artigos e livro didático intitulado Atividades experimentais de química geral. ${ }^{62}$

Além dos autores mencionados, Márlon Herbert Flora Barbosa Soares, Luiz Henrique Ferreira, Marcelo Brito Carneiro Leão, Agnaldo Arroio, Marcelo Giordan e Salete Linhares Queiroz não foram supervisionados por formadores já inseridos na área de Educação em Química, e apresentam produção significativa na terceira década, inclusive na formação de novos formadores, com todos eles tendo orientado alunos de pós-graduação no período.

Márlon Herbert Flora Barbosa Soares não teve a produção em destaque na segunda década do ENEQ, porém, na terceira, sua produção sobressaiu-se entre as demais. Com efeito, foram publicados mais de duas dezenas de artigos, sete deles na QNEsc. O livro Jogos em ensino de química: teoria, métodos e aplicações ${ }^{63}$ é também de sua autoria, além da supervisão de dissertações de mestrado e teses de doutorado. Luiz Henrique Ferreira publicou mais de uma dezena de artigos, seis deles na QNEsc, e supervisionou dissertações de mestrado e teses de doutorado. Na sequência, Marcelo Brito Carneiro Leão publicou mais de uma dezena de artigos, um na QNEsc, e supervisionou dissertações de mestrado e tese de doutorado.

Agnaldo Arroio publicou mais de duas dezenas de artigos, um deles na QNEsc e cinco na Química Nova, além de ter supervisionado dissertações de mestrado e tese de doutorado. Marcelo Giordan publicou mais de duas dezenas de artigos, cinco deles na QNEsc e o livro Computadores e linguagens nas aulas de ciências: uma perspectiva sociocultural para compreender a construção de significados,${ }^{64}$ além de ter supervisionado dissertações de mestrado e teses de doutorado.

Salete Linhares Queiroz publicou mais de três dezenas de artigos, oito deles na Química Nova e dois na QNEsc. No período, supervisionou dissertações de mestrado e tese de doutorado, sendo ainda coautora dos livros: Comunicação e linguagem científica: guia para estudantes de química, ${ }^{18}$ Estudo de casos no ensino de química; ${ }^{65}$ Iniciação científica no ensino superior: funcionamento e contribuições. ${ }^{66}$

Com relação às instituições de origem dos autores de maior destaque, nesse período, diferentemente dos demais, verifica-se a presença marcante da USP, instituição sede de cinco, dentre dezenove deles: Agnaldo Arroio, Marcelo Giordan, Maria Eunice Ribeiro Marcondes, Rosebelly Nunes Marques e Salete Linhares Queiroz.
Em uma retrospectiva que considere também os autores de maior protagonismo no ENEQ na primeira década, verifica-se a ausência de publicações na terceira década apenas de Sérvulo Folgueras Domínguez, falecido em 2002. A atuação de Romeu Cardozo Rocha-Filho resulta em apenas uma publicação na QNEsc, o que sinaliza o significativo decréscimo de suas contribuições para a área, comparativamente às décadas anteriores.

Em contraponto, Roberto Ribeiro da Silva continuou atuante, com a produção de mais de uma dezena de artigos, três deles na QNEsc, e dois na Química Nova, além de supervisão de dissertações de mestrado. Da mesma forma, Dácio Rodney Hartwig publicou mais de uma dezena de artigos, sete deles na QNEsc, e supervisionou dissertações de mestrado e teses de doutorado.

Attico Inacio Chassot também continuou colaborando vigorosamente para a produção na área, com mais de três dezenas de artigos, sendo cinco deles na QNEsc, além da supervisão de dissertações de mestrado e teses de doutorado, e autoria de livros que contam com mais de uma edição, como A ciência é masculina? É sim, senhora! ${ }^{67}$ e Educação conSciência. ${ }^{68}$

Diante do exposto no presente tópico, é possível constatar, quando tomamos o recorte temporal por décadas, quatro grupos distintos de autores que contribuíram com o evento:

- O primeiro é composto por autores pioneiros, com presença marcante no ENEQ principalmente na primeira década, que inclui Attico Inacio Chassot, Sérvulo Folgueras Domínguez, Dácio Rodney Hartwig, Romeu Cardozo Rocha-Filho e Roberto Ribeiro da Silva. Os autores deste grupo, apesar de perderem protagonismo no evento, continuaram, na sua grande maioria, oferecendo contribuições muito relevantes para a consolidação da área em questão nas duas décadas seguintes.

- O segundo é formado por autores que mantiveram posição de destaque no ENEQ não somente na primeira década, mas também na segunda e/ou na terceira década, que inclui Roseli Pacheco Schnetzler, Eduardo Fleury Mortimer, Maria Eunice Ribeiro Marcondes e Rosária da Silva Justi. A contribuição de todos os que pertencem a esse grupo mostra-se perene e importante para a consolidação da área.

- O terceiro é formado por autores que ganharam protagonismo no ENEQ, principalmente na segunda década, e permaneceram apresentando aportes ao ensino de química na terceira década, com destaque para lideranças que despontaram em várias regiões do Brasil, que inclui Djalma de Andrade, José Cláudio Del Pino, Rejane Martins Novais Barbosa, Andréa Horta Machado, Murilo Cruz Leal e José Luis de Paula Barros Silva.

- O quarto é composto por autores que se destacaram, principalmente, na terceira década, alguns, inclusive, orientados em suas teses de doutorado por autores do primeiro e do segundo grupo. Observamos dois perfis principais, no que diz respeito à formação acadêmica desses autores: os oriundos de grupos de pesquisa liderados pelos pioneiros, com formação específica na área de Educação em Química, como é o caso de Ana Luiza de Quadros, Antonio Lauxen e Gerson de Souza Mól; os oriundos de áreas específicas da Química, com suas teses de doutorado defendidas sobre temáticas desse campo de conhecimento, que migraram para área de Educação em Química, entre eles estão Luiz Henrique Ferreira, Marcelo Brito Carneiro Leão, Agnaldo Arroio, Marcelo Giordan, Salete Linhares Queiroz e Simara Maria Tavares Nunes. Também existem dois autores com perfis distintos dos demais: Rosebelly Nunes Marques e Márlon Herbert Flora Barbosa Soares. A primeira defendeu tese na área de Educação e também na área de Química, enquanto o segundo defendeu sua tese sobre a temática do ensino de química, em um Programa de Pós-graduação em Química e sob supervisão de orientador atuante principalmente na área de Química. 
A investigação da autoria dos trabalhos dos ENEQ, como havia sido especulado anteriormente, permitiu que se verificasse de forma ainda mais contundente a consolidação da área de Educação em Química, especialmente no que diz respeito ao indicador vinculado à existência de profissionais que nela atuam. Conforme mostram as discussões realizadas nesse tópico, no cenário nacional a dedicação de tais profissionais tem se dado de forma constante e vigorosa ao longo do período analisado, com impactos muito positivos, que impulsionam a área, a partir do incremento da produção acadêmica, da formação de novos formadores (com ampliação e diversificação de linhas de pesquisa) e da produção de materiais didáticos, dentre outros resultados de natureza similar.

Ademais, a contraposição das informações presentes no primeiro tópico, com relação às comissões organizadoras do ENEQ, e as do segundo tópico, revela vários autores que, além da produção considerável em número de trabalhos, tiveram participação nas comissões, ou seja, contribuíram nas duas frentes, corroborando o envolvimento na área, tais como: Maria Eunice Ribeiro Marcondes, Attico Inacio Chassot, Luiz Otávio Fagundes Amaral, Eduardo Fleury Mortimer, Roseli Pacheco Schnetzler, Rosária da Silva Justi, Lilavate Izapovitz Romanelli, Roberto Ribeiro da Silva, Djalma Andrade, José Cláudio Del Pino, Andréa Horta Machado, Rejane Martins Novais Barbosa, José Luis de Paula Barros Silva, Márlon Herbert Flora Barbosa Soares, Luiz Henrique Ferreira, Luiz Antônio Andrade de Oliveira, Marcelo Brito Carneiro Leão, Agnaldo Arroio, Salete Linhares Queiroz, Marcelo Giordan e Gerson de Souza Mól.

\section{CONSIDERAÇÕES FINAIS}

Este trabalho foi realizado com o propósito de contribuir para o entendimento sobre a consolidação da área de Educação em Química no Brasil, tomando por base uma narrativa sobre os ENEQ, de 1982 a 2018, assim como a investigação da autoria dos trabalhos apresentados entre 1982 e 2010 . A discussão desenvolvida para tanto, pautada em indicadores propostos por Taber, ${ }^{16}$ mostrou fatores que determinaram a sua consolidação e também algumas das suas características mais marcantes. Cabe destacar que as nuvens de tags geradas no artigo tiveram como propósito a produção de imagens visuais simples ${ }^{69}$ que sintetizam resultados relevantes, não tendo sido creditado a elas a prerrogativa de trazer ao texto indícios substanciais para a avaliação dos referidos resultados.

A análise da autoria dos trabalhos evidenciou a existência de grupos de educadores que, ao longo dos anos, ofereceram não só sustentação inicial para a área em questão, mas também subsídios para que se desenvolvesse. A formação de recursos humanos em cursos de mestrado e doutorado, principalmente por parte dos pioneiros, foi de fundamental importância, permitindo a disseminação de iniciativas voltadas ao ensino de química em todo o país, assim como a constituição de grupos de pesquisa imbuídos da tarefa de investigar inúmeros aspectos que permeiam esse ensino.

É preciso destacar fortemente que o recorte de estudo assumido, no caso, os anais dos ENEQ ao longo de três décadas, implica em limitações na indicação de um amplo coletivo de pessoas que possam ter contribuído para a área de Educação em Química de forma tão ou mais consistente que os educadores citados neste manuscrito. No entanto, mesmo para alcançar este resultado, com as suas notáveis fragilidades, foi necessária a análise de mais de 2000 trabalhos apresentados nos ENEQ, o que acabou por possibilitar a realização de um movimento que pode permitir, ainda que de forma singela, a preservação da memória da área.

Por fim, a análise da quarta década do evento, finalizada no corrente ano com a concretização do XX ENEQ,${ }^{6}$ apresenta-se como um desafio com potencial para trazer novos e importantes elementos à narrativa aqui apresentada.

\section{AGRADECIMENTOS}

À Universidade Estadual do Sudoeste da Bahia (UESB), pela concessão de ajuda de custo à primeira autora, por meio do Edital $n .^{\circ}$ 003/2015, e ao Conselho Nacional de Desenvolvimento Científico e Tecnológico (CNPq), Processo 304974/2020-0.

ÀAgustina Rosa Echeverría, Dácio Rodney Hartwig, Luiz Otávio Fagundes Amaral, Maria Eunice Ribeiro Marcondes, Maurivan Güntzel Ramos e Romeu Cardozo Rocha-Filho, que possibilitaram ao segundo autor o acesso aos primeiros anais dos ENEQ, sem o qual a realização deste trabalho não teria sido possível.

\section{REFERÊNCIAS}

1. Alexandrino, D. M.; Queiroz, S. L. REEC: Revista Electrónica de Enseñanza de las Ciencias 2020, 19, 638.

2. Petrucci-Rosa, M. I; Rossi, A.V. Educação química no Brasil: memórias, políticas e tendências, Editora Átomo: Campinas, 2012.

3. Schnetzler, R. P. Quim. Nova 2002, 1, 14.

4. Alexandrino, D. M. Tese de Doutorado. Universidade de São Paulo, Brasil, 2019.

5. Soares, M. H. F. B.; Mesquita, N. A. S.; Rezende, D. B. Quim. Nova 2017, 40, 65 .

6. https://sbenq.org.br/category/boletins-sbenq/, acessada em outubro 2021.

7. Gurgel, C. M. A.; Ciência \& Educação 2002, 8, 263.

8. Ramos, M. G.; Massena, E. P.; Marques, C. A.; Quim. Nova Esc. 2015, 37, 116.

9. Echeverría, A. R.; Quim. Nova Esc. 2004, 20, 25.

10. Editorial, Quim. Nova Esc. 2010, 32,3.

11. Porto, P. A.; Queiroz, S. L.; Santos, W. L. P.; Quim. Nova Esc. 2015, 37, 3.

12. Caderno de Programação do $18^{\circ}$ Encontro Nacional de Ensino de Química, Florianópolis, Brasil, 2016, disponível em http://www. eneq2016.ufsc.br/, acessada em outubro 2021.

13. Porto, P. A.; Queiroz, S. L.; Quim. Nova Esc. 2016, 38, 199.

14. Porto, P. A.; Queiroz, S. L.; Quim. Nova Esc. 2018, 40, 143.

15. Porto, P. A.; Queiroz, S. L.; Quim. Nova Esc. 2019, 41, 3.

16. Taber, K. S.; Disciplinary and Interdisciplinary Science Education Research 2019, $1,1$.

17. Fensham, P. J.; Defining an identity: the evolution of science education as a field of research, Kluwer Academic Publishers: Dordrecht, 2004.

18. Oliveira, J. R. S.; Queiroz, S. L.; Comunicação e linguagem científica: guia para estudantes de química. Editora Átomo: Campinas, 2007.

19. http://www.quimica.ufpr.br/eduquim/eneq2008/i_momadiq-resumos. htm\#m012, acessada em outubro 2021.

20. http://www.eneq2016.ufsc.br/, acessada em outubro 2021.

21. Domínguez, S. F.; As experiências em química, Edart: São Paulo, 1975.

22. Domínguez, S. F.; Classificação periódica dos elementos, IBECC: São Paulo, 1964.

23. Domínguez, S. F.; Reações Química, Edart: São Paulo, 1973.

24. Domínguez, S. F.; Orbitais: estrutura de átomos, moléculas e cristais, Edart: São Paulo, 1967.

25. Rocha-Filho, R. C.; Grandezas e unidades de medida: o sistema internacional de unidades, Ática: São Paulo, 1988.

26. Rocha-Filho. R. C.; Bocchi, N.; Silva, R. R.; Introdução à química experimental, McGraw-Hill do Brasil: São Paulo, 1990.

27. Marcondes, M. E. R.; Ciência e Cultura 1981, 3, 369.

28. Marcondes, M. E. R.; Subsídios para implementação do guia curricular de química para o $2^{\circ}$ grau, v. III, São Paulo: FUNBEC, 1980.

29. Sicca, N. A. L.; Paidéia FFCLRP-USP, 1997, 158. 
30. Chassot, A. I.; A educação no ensino de química, $1^{\text {a }}$ ed., Unijuí: Ijuí, 1990.

31. Schnetzler, R. P.; Tese de Doutorado, University of East Anglia, Inglaterra, 1987.

32. Schnetzler, R. P.; Informe Educação para a Ciência, 1985, 6, 13

33. Mazon, A. B.; Dissertação de Mestrado, Universidade de Campinas, Brasil, 1989.

34. Senapeschi, A. N.; Tolentino, M.; Silva, R. R.; Rocha-Filho, R. C.; Quim. Nova 1988, 11, 234.

35. Tolentino, M.; Silva, R. R.; Rocha-Filho, R. C.; Senapeschi, A. N.; Quim. Nova 1988, 11, 340 .

36. Silva, R. R.; Rocha-Filho, R. C.; Senapeschi, A. N.; Tolentino, M.; Quim. Nova 1989, 12, 66 .

37. Hartwig, D. R.; Rocha-Filho, R. C.; Rodrigues, R.; Quim. Nova 1982 5,60 .

38. Hartwig, D. R.; Rocha-Filho, R. C.; J. Chem. Educ. 1983, 60, 591.

39. Rocha-Filho, R. C.; Hartwig, D. R.; Quim. Nova 1988, 11, 222.

40. Hartwig, D. R.; Dominguez, S. F.; Quim. Nova 1985, 8, 116.

41. Tolentino, M.; Rocha-Filho, R. C.; Silva, R. R.; $O$ azul do planeta: um retrato da atmosfera terrestre. Moderna: São Paulo, 1995.

42. Rocha-Filho, R. C.; Silva, R. R.; Introdução aos cálculos da química. McGraw-Hill: São Paulo, 1992.

43. Chassot, A. I.; Catalisando transformações na educação, Unijuí: ljuí, 1993.

44. Ciência, ética e cultura na educação; Chassot, A. I., Oliveira, R. J., orgs.; Editora Unisinos: São Leopoldo, 1998.

45. Hartwig, D. R.; Souza, E.; Motta, R. M.; Química 1: química geral e inorgânica. Scipione: São Paulo, v 1, 1999.

46. Hartwig, D. R.; Souza, E.; Motta, R. M.; Química 2: físico química. Scipione: São Paulo, v 2, 1999.

47. Hartwig, D. R.; Souza, E.; Motta, R. M.; Química 3: química orgânica. Scipione: São Paulo, v 3, 1999.

48. Domínguez, S. F.; Metodologia e prática de ensino de química. [s.n.] São Carlos, 1994.

49. Mol, G. S.; Santos, W. L. P.; Silva, E. N. F.; Matsunaga, R.; Silva, R. R.; Farias, S. B.; Santos, S. M. O; Dib, S. M. F.; Química na sociedade: projeto de ensino de química em um contexto social, Editora da UnB: Brasília, 1998.

50. Interações e transformações I: química - ensino médio; Pitombo, L. R. M., Marcondes, M. E. R., coord.; EDUSP: São Paulo, 1993.
51. Interações e transformações II: química - ensino médio; Pitombo, L. R. M., Marcondes, M. E. R., coord.; EDUSP: São Paulo, 1995.

52. Interações e transformações III: química - ensino médio; Pitombo, L. R. M., Marcondes, M. E. R., coord.; EDUSP: São Paulo, 1998.

53. Santos, W. L. P.; Schnetzler, R. P.; Educação em química: compromisso com a cidadania, Unijuí: ljuí, 1997.

54. Romanelli, L. I.; Justi, R. S.; Aprendendo química, Unijuí: ljuí, 1999.

55. Mortimer, E. F.; Linguagem e formação de conceitos no ensino de ciências, Editora da UFMG: Belo Horizonte, 2000.

56. Schnetzler, R. P.; Oliveira, C.; Orientadores em foco: o processo da orientação de teses e dissertações em educação, Liber Livro: Brasília, 2010 .

57. Mortimer, E. F.; Scott, P. H.; Meaning making in secondary science classroom, Open University Press/McGraw Hill: Maidenhead, 2003.

58. Mortimer, E. F.; Lenguaje y formación de conceptos en la enseñaza de las ciencias, Antonio Machado Libros: Madrid, 2006.

59. Mortimer, E. F.; Machado, A. H.; Química para o ensino médio. Scipione: São Paulo, 2002.

60. Quadros, A. L.; Carvalho, M. E. D.; Siebald, H. G. L.; Introdução a química. Editora da UFMG: Belo Horizonte, 2008.

61. Mol, G. S.; Santos, W. L.; Matsunaga, R. T.; Dib, S. M. F.; Castro, E. N. F.; Silva, G. S.; Santos, S. M. O.; Farias, S. B.; Química \& sociedade. Nova Geração: São Paulo, 2005.

62. Lauxen, A. A.; Zoch, A. N.; Vaniel, A. P. H.; Mistura, C. M.; Prado, E. A.; Ortiz, J. C.; Santin, J. A.; Linck, M. R.; Friedrich, M. T.; Atividades experimentais de química geral. Berthier: Passo Fundo, 2010.

63. Soares, M. H. F. B.; Jogos em ensino de química: teoria, métodos e aplicações. Ex Libris: Guarapari, 2008.

64. Giordan, M.; Computadores e linguagens nas aulas de ciências: uma perspectiva sociocultural para compreender a construção de significados, 1a ed., Unijuí: Ijuí, 2008.

65. Sá, L. P.; Queiroz, S. L.; Estudo de casos no ensino de química, Átomo: Campinas, 2009.

66. Massi, L.; Queiroz, S. L.; Iniciação científica no ensino superior: funcionamento e contribuições, Átomo: Campinas, 2010.

67. Chassot, A. I.; A ciência é masculina? É sim, senhora!, $1^{\text {a }}$ ed., Unisinos: São Leopoldo, 2003.

68. Chassot, A. I.; Educação conSciência, $1^{\text {a }}$ ed., EDUNISC: Santa Cruz do Sul, 2003.

69. Miley, F.; Read, A.; Journal of the Scholarship of Teaching and Learning 2011, 2, 91 . 